\title{
The New Final Frontier: A Case Study Analysis of Private Sector's Increasing Role in the Space Industry
}

\author{
Damini Rana ${ }^{1}$ and Mritunjay Sharma ${ }^{\#}$ \\ ${ }^{1}$ Delhi Public School RK Puram, Delhi, India \\ \#Advisor
}

$\underline{\text { ABSTRACT }}$

Historically, any endeavors involving the term 'space' were perceived as operations undertaken by large government organizations with an emphasis on the scientific aspect, rather than a business one. However, over the last two decades, the structure of the space industry is rapidly being transformed and privatized due to the growth in commercial applications and the catalyzing entry of billionaires such as Elon Musk and Jeff Bezos. This paper offers a case study analysis of the private sector's growing influence in the space industry through a combination of a quantitative analysis and an in-depth review of the surrounding literature. The results show that the commercial economy now accounts for almost $80 \%$ of the monetary size of the space industry and is expected to drive most of the growth in future. Further, a forecast of the future size of the space economy suggests it could touch almost US\$1.5 trillion by 2040, dominated by the private sector. A regression analysis conducted to assess the quantum of private sector investment that will be required if the industry is to achieve its forecasted potential in the upcoming decades revealed that private investments must go up to US\$48billion by 2025 .

\section{Introduction: Historical Background and Entry of the Private Sector into Outer Space}

Humans' "trysts" with space begun in 1957 with USSR's launch of Sputnik-1, elevating tensions during the cold war [1] and initiating the "space race" between the USSR and the USA. This in turn led to the US's Apollo moon landings in the late 1960s. Although the exploration of space at that stage was led primarily by the joint efforts of the political, defense and scientific communities, they worked for the governments through specially created agencies.

The initial development of the space industry was thus founded on a model that involved governments directly [2]. The US government's Apollo program created a public sector-led business model of the space industry, which would prevail for the subsequent decades. Essentially, governments at the national level, along with their respective agencies, led developments within the space industry, in terms of knowledge, technology and capabilities. They directly supported the construction of infrastructure, including ground stations, launch vehicles, and satellites facilities.

For these governments, their forays into space revolved around the pursuit of national glory and scientific knowledge through space exploration and human spaceflight. This enabled their defense establishments to gain a military high ground through use of satellites for surveillance and communication. Moreover, governments and their regulatory agencies tightly controlled the economic exploitation of satellites to provide civil communication (primarily for telephony and television) and Earth observation (EO) for meteorology [3].

Continued technological developments around the late 1970s led to promising business opportunities in the fields of telecommunication and broadcasting, accelerating the demand for satellite services across organizations and countries. New organizations, such as EUTELSAT in Europe and INSAT in India, emerged to create and manage such satellite services and offer them for commercial use. However, the number of private players involved in the space economy remained limited [4]. 
It is pertinent to note that the parallel developments in NASA also contributed to the rise of the private space sector. After the Apollo missions ended in 1972, NASA shifted its focus towards the Space Shuttle, with the first flight of the Columbia space shuttle in 1981 [5]. The shuttle made over 100 successful flights in the following decades and participated in the construction of the International Space Station (ISS) and the construction of the Hubble Space Telescope [6]. These endeavors enabled the US to demonstrate its technological prowess during that period. But the high costs of the NASA space program and two tragic accidents - the Space Shuttle Challenger accident which resulted in the death of all its 7 crew members in 1986 and the Space Shuttle Columbia accident in 2003 [7] — led to its eventual closure. In 2004, the US President's Commission on Implementation of United States Space Exploration Policy (2004) concluded: "NASA's role must be limited to only those areas where there is irrefutable demonstration that only government can perform the proposed activity." [8]

A more rapid stage of commercialization commenced in the late 1990s. Enhancements in digital data handling and analytical capabilities made space technologies \& assets increasingly important in diverse fields such as communications, broadcasting, navigation, meteorology and Earth observation. Satellites were also getting cheaper, lighter and better, and hence commercially viable for more organizations and applications.

The first major private investment in space happened between 1997 and 2002, when Motorola deployed Iridium, a satellite constellation with 66 satellites, in the Low Earth Orbit (LEO), aiming to provide mobile telephone communication anywhere on the planet. Iridium was privately funded at over US\$5 billion but could not meet its revenue targets and went bankrupt. Iridium did, however, meet its technical and operational targets, setting a precedent in illuminating the potential of the private sector [9]. Additionally, after emerging from bankruptcy through a restructuring, Iridium continues to operate the leading LEO satellite constellation to date; it was only last year that the old satellites were fully replaced by next-generation satellites [10].

The Internet boom during the late 1990s created a new breed of internet billionaires who believed in the transformative power of technology and sought to deploy their wealth in pursuit of their radical vision of having "millions of people living and working in space" (as per Jeff Bezos, founder of Amazon and Blue Origin) [11] or colonizing Mars (Elon Musk's vision for SpaceX). Even those without the vast resources and the grandiose visions of Bezos and Musk saw opportunities in the space industry driven by the proliferation of satellite television, mobile telecommunication and the Internet across the world.

The trend only accelerated with the introduction of the smartphone in 2007, initiating a new era of massification of mobile broadband and new commercial applications that leveraged and were highly dependent on satellite communications. For instance, Global Positioning System (GPS) enabled a range of downstream applications on smartphones.

Concomitantly, as the declining costs of commercial launches and satellite manufacturing lowered the barriers of entry [12], more and more entrepreneurs ventured into this domain to build what is often referred to as the "New Space economy". It functions with slightly different and more innovative goals compared to its governmental counterparts. NASA's objectives have historically been to expand human knowledge through new scientific discoveries, extend human presence deeper into space and to the Moon for sustainable long-term exploration and utilization, address National challenges, and catalyze economic growth [13]. In contrast, a widely shared goal among commercial space's leaders has been the achievement of a large-scale, mostly self-sufficient, developed space economy [8]. The vision of New Space and technologies is to create the next set of futuristic services and industries: space tourism, asteroid mining, additive manufacturing within space and so on. This new space economy will move opportunities beyond traditional launch and satellite services, and open up new long-term economic and investment opportunities. Clearly, the private sector thrust into space has the potential to transform the future of space and maybe even humanity over the longer term.

This research study thus sought to delve into the extent of contribution of the private sector to the growth of the space economy during the $21 \mathrm{st}^{\mathrm{st}}$ century.

\section{Description of the Research Study}


The aim of this research study was to conduct a case study analysis to determine the extent to which the private sector had contributed to the accelerated growth of the space economy over the past two decades. More specifically, both quantitative and qualitative data were gathered and analyzed to provide a comprehensive picture of the phenomenon of the transformation of the space economy through private sector investments. Together, they offered mutually reinforcing perspectives of the extraordinary impact the participation of the private sector had on the space economy.

Case studies involve gathering and analyzing data from a variety of sources [14]. Thus, they can be invaluable in understanding and extending experience with a subject. In this research study, the case study analysis comprised the adoption of quantitative and qualitative approaches. Data obtained from the Space Foundation Report [15] was analyzed to evaluate the effect of the commercial space economy on the growth of the space economy, as compared to the government space economy. Furthermore, the literature surrounding the developments of the space economy and the influence of the different factors driving private sector investments in space was analyzed in relation to the quantitative findings generated.

Lastly, in accordance with the aforementioned factors and assumptions based on current estimates for future growth, a forecast was made on the likely size of commercial and government space economies by 2040 . A linear regression was conducted to determine a quantitative prediction of the impact of the size of private investments on the size of the commercial space economy. This regression was subsequently used to forecast the future investments and initiatives that will be required if the industry is to achieve its forecasted potential in the upcoming decades

\section{Quantitative Assessment}

Several organizations have estimated the size of the space economy, and these vary depending on the methodology. A report prepared for the Satellite Industry Association (SIA) by Bryce Space and Technology in May 2019 estimated the global space economy to be $\$ 360$ billion. The Space Foundation, in its report published in July 2019, estimated the global space economy to be about $\$ 415$ billion in 2018 . The two reports also differed in estimated growth: the SIA report saw growth of $3 \%$ in 2018 , versus $8 \%$ in the Space Foundation report. [16]

While some elements of what should be counted in the sizing are consistent such as government expenditures on space, revenues from goods and services provided from space, manufacturing and operating space hardware, global navigation satellite systems (GNSS), and other ground-based equipment for receiving signals from space, there are areas where these estimates can be quite broad (for instance, revenues of all commercial uses of GPS including revenues for services like Uber) [17].

This report relied on data on the size of the space economy from The Space Foundation, as provided in Table 1. This was used to evaluate the relative importance of the commercial sector vis-à-vis the government sector on the space economy over the last 15 years [15].

TABLE I

Growth in Global Space Economy (US\$ Billion)

\begin{tabular}{|l|l|l|l|l|l|}
\hline Year & Commercial & \multicolumn{3}{|l|}{ Government } & Total \\
\hline & & Total & $\boldsymbol{U S}$ & Non - US & \\
\hline 2005 & 125 & 51 & 37 & 14 & 176 \\
\hline 2006 & 151 & 55 & 40 & 15 & 206 \\
\hline 2007 & 167 & 57 & 40 & 17 & 224 \\
\hline 2008 & 171 & 65 & 44 & 21 & 236 \\
\hline 2009 & 162 & 72 & 46 & 26 & 234 \\
\hline 2010 & 170 & 74 & 47 & 27 & 244 \\
\hline 2011 & 193 & 78 & 48 & 30 & 271 \\
\hline
\end{tabular}




\begin{tabular}{|l|l|l|l|l|l|}
\hline 2012 & 208 & 77 & 47 & 30 & 285 \\
\hline 2013 & 228 & 74 & 42 & 32 & 302 \\
\hline 2014 & 251 & 79 & 43 & 36 & 330 \\
\hline 2015 & 246 & 77 & 45 & 32 & 323 \\
\hline 2016 & 262 & 83 & 48 & 35 & 345 \\
\hline 2017 & 308 & 75 & 43 & 32 & 383 \\
\hline 2018 & 329 & 86 & 48 & 38 & 415 \\
\hline 2019 & 337 & 87 & 47 & 40 & 424 \\
\hline CAGR 2005-2019 & $\mathbf{7 . 3 \%}$ & $\mathbf{3 . 9 \%}$ & $\mathbf{1 . 7 \%}$ & $\mathbf{7 . 7 \%}$ & $\mathbf{6 . 5 \%}$ \\
\hline CAGR 2009-19 & $\mathbf{7 . 6 \%}$ & $\mathbf{1 . 9 \%}$ & $\mathbf{0 . 3} \%$ & $\mathbf{4 . 3 \%}$ & $\mathbf{6 . 1 \%}$ \\
\hline
\end{tabular}

The above data indicates that the space economy has grown from US\$176 billion in 2005 to US\$424 billion in 2019 (at a cumulative annual growth rate or CAGR of 6.5\%). Within the same period, the commercial economy's contribution to the sector had risen from US\$125 billion to US\$337 billion (at a CAGR of 7.3\%). This is more than double the CAGR of the government activity in this sector, which grew at a CAGR of 3.9\% for the same period based on an increase from US\$51 billion to US\$87 billion.

Clearly, the role of the government in the space economy had declined significantly during this period. Particularly from 2009 onwards, and coinciding with the global financial crisis, the rate of growth of the government economy had declined sharply to only $\sim 1.9 \%$ per annum, while the growth rate of the commercial economy had increased to $7.6 \%$ per annum. The US government witnessed a sharp contraction to just $0.3 \%$ p.a., while other governments had also stepped back significantly, thus ceding space to the private sector to drive the space economy.

From these figures, the rapid increase in the private sector's involvement in the space economy is evident. This radical shift in influence and the factors responsible for it are examined qualitatively in the next section, and together provide a comprehensive view of the future of the space economy.

\section{Discussion: Growth Drivers of Private Investments}

Three factors have been identified as key drivers that have propelled growth in private sector interest and investments in space over the last two decades:

Increase in opportunities for private players

Reduction in cost of access to space

Success of SpaceX

\section{A. Increase in Opportunities for Private Players}

Substantial regulatory, commercial and technological changes took place in the late 1990s and early 2000s that enhanced the opportunities and incentives for private sector participation in space. This in turn, led to creation of many new private companies focused on space.

\section{Regulatory Developments}

As discussed earlier, in the initial decades of its development, most of the space economy was controlled by the government. Production and ownership of satellites began to be privatized in the 1970s, however all commercial satellite launches in the United States were controlled by NASA. While private vendors were involved in launch vehicle development, NASA owned the space shuttle. [2] 
This started to change when the Commercial Space Act was passed in US in 1998. The purpose of this act was "to encourage the development of a commercial space industry in the United States." [18]

The space shuttle Columbia accident in 2003 and subsequent closure of the space shuttle program led to a vacuum in US launch capabilities and pushed NASA to facilitate a greater role for the private sector by awarding contracts to private companies to ferry cargo and humans to and from the International Space Station. The Commercial Space Launch Amendments Act of 2004 was also enacted that legalized private space flights and curtailed the role of NASA. [8]

Hence, around the start of this millennium, the regulatory environment, particularly in the US, turned favorable for private sector participation.

\section{Commercial \& Technological Developments}

Significant commercial and technological developments also took place in the 1990s. Second Generation (2G) mobile telephony was launched in 1991 and its rapid global growth transformed the scale and scope of telecommunication. The invention of the world wide web in 1990 made the internet accessible for masses and created a plethora of new business opportunities. Advancement in digital electronics, communication and internet increased the commercial applications and revenues from space, making it a lucrative proposition for the private sector to enter and invest.

This ‘technology boom' also created a new breed of first-generation billionaires who understood the power of technology and were willing to invest in risky, futuristic, technology-led ventures

\section{Emergence of Private Sector Companies}

These developments led to a flurry of private sector activity in space. Jeff Bezos of Amazon founded Blue Origin in 2000, followed by Elon Musk starting SpaceX in 2002.

Communications satellite providers, INTELSAT and EUTELSAT, joined forces to become a private company in 2001, while Boeing merged with Lockheed Martin to create United Launch Alliance in 2006 [4]. A sampling of some major companies that have emerged in the new millennium and are driving this new Space Economy are provided below in Table 2. This is, of course, a partial list and there are several other companies pursuing opportunities in the space industry. Established older companies like Boeing Aerospace and Arianespace are not mentioned here, but they too continue to be important players in many of these new areas, in addition to their traditional launch and satellite businesses.

TABLE 2

Selected Companies Focused on Space Created in the last 20 years

\begin{tabular}{|l|l|l|}
\hline Company & Founding year & Product / Service \\
\hline Space Access & 2000 & Launch vehicles and engines, space tourism \\
\hline Blue Origin & 2002 & Reusable launch vehicles, colonization \\
\hline SpaceX & 2006 & Orbital launch services \\
\hline United Launch Alliance & 2004 & Space Tourism, Commercial Flights \\
\hline Virgin Galactic & 2010 & Micro Satellite Operator, Earth Imaging \& Sensing \\
\hline \multicolumn{2}{|l|}{ Micro Satellite Operator, Earth Observation, Data Analytics } \\
\hline Remote Sensing & 2012 & Satellite constellations \\
\hline Spire Global & 2015 & \\
\hline \multicolumn{2}{|l|}{} \\
\hline LEO Communication Constellations & Starlink &
\end{tabular}




\begin{tabular}{|l|l|l|}
\hline OneWeb & 2012 & Satellite constellations \\
\hline Project Kuiper & 2019 & Satellite constellations \\
\hline \multicolumn{2}{|l}{} \\
\hline Others & \multicolumn{2}{|l|}{} \\
\hline Planetary Resources & 2010 & Asteroid Mining \\
\hline Deep Space Industries & 2013 & Spacecraft to travel from LEO to deep space \\
\hline Bigelow Aerospace & 1999 & Inflatable space habitats \\
\hline Made in Space & 2010 & Additive/3D Manufacturing in Space \\
\hline Axiom & 2015 & Commercial spacecraft building off ISS \\
\hline
\end{tabular}

Data sourced from [8][19]

\section{B. Declining Costs of Access to Space}

Historically, the space opportunities were accessed by launching large, heavy satellites in geosynchronous orbits on massive launch vehicles. Both satellites and launch vehicles were expensive to manufacture and launch leading to high cost of access to space. This was a key impediment to opening the space economy to a larger number of investors and applications.

Two major developments have taken place over the last few decades. Firstly, the cost of launching a given weight of payload in space has declined substantially. Secondly, the payload itself, viz., the satellites, have become lighter, cheaper and better in terms of performance.

This enabled many more organizations to launch and own satellites for a wider range of applications. This trend has, and will, continue to unleash a range of entrepreneurial activity in space. As per Autry [20] space tourism, material development, pharmaceutical research, power generation, communication, earth imaging and national security all have "killer apps" just waiting for reliable and affordable access to space.

Both factors, decline in cost of launch and evolution of satellites are further elaborated below.

\section{Decline in Launch Costs}

For several decades, the high cost of launching a payload in space was a big hurdle to its democratization and restricted access to space to only select applications by large enterprises/governments.

However, costs of launching a payload in space have gone down by $~ 90 \%$ starting from the late 1990s till the launch of Falcon Heavy, as shown in Table 3 [21]. In fact, if SpaceX achieves its stated targets with its new launch vehicle, the Starship - a fully reusable launch vehicle - the cost of the launch could plummet by as much as 10 times, as compared to the costs of 2010's Falcon 9 [22]. While Starship is still under testing, Musk expects it to be operational by 2021 .

TABLE 3

Evolution of Payload Launch Costs to LEO in current US\$ (2018)

\begin{tabular}{|l|l|l|}
\hline Year & Cost of Launch $/ \mathbf{k g}$ & Comments \\
\hline 1998 & $\$ 11700$ & Delta III from Boeing \\
\hline 2010 & $\$ 2700$ & Falcon 9 from SpaceX \\
\hline 2018 & $\$ 1400$ & Falcon Heavy from SpaceX \\
\hline 2022 & $\$ 20-\$ 270$ & Elon Musk statement on Starship costs [22] \\
\hline
\end{tabular}


It is evident from Table 3 that SpaceX has played a key role in driving the reduction in the costs of launch. Its design philosophy has revolved around the principle of simplicity - a mechanism that leads to lowered costs and increased reliability. SpaceX's effectiveness in lowering costs can also be attributed to the in-house execution of most of the production process within a singular facility, low reliance on external contractors and focus on launch vehicle reuse [23], [24].

It is estimated by Nasa that launch costs may be further reduced with further reuse of launch vehicles, increase in demand, increased commercial competition, better management and engineering, along with technical advances [21].

\section{Evolution of Satellites}

Historically, most satellites were launched in geosynchronous orbits. They weighed 1000-1500 kg and took substantial time and cost to manufacture. This led to less competition within this domain, and the Satellite business model entailed investing to get a satellite built and launched, followed by getting a steady cash flow for its life of $\sim 15$ years. [3]. Only a few satellites were launched every year and they would stay in orbit for 15+ years. This meant limited requirements for satellite manufacturing, launch and management translating to low innovation and investments in space.

However, as Sweeting [3] elaborates, by 2000, advances in digital technologies led to emergence of smaller satellites, often referred to as smallsats. These provided good performance at relatively lost cost and weight and could be launched in Low Earth Orbit. Some of the smallest of these satellites are known as CubeSats - measuring roughly 10x10x10cm and weighing about $1 \mathrm{~kg}$. Multiple CubeSats can be put together to add more functionality. These smaller satellites could also be launched as a secondary payload, further lowering the costs and time to launch. In fact, the Indian Space Research Organisation (ISRO) created a record in February 2017 by successfully launching 104 satellites, including India's earth observation satellite on a single rocket mission [25]. This meant that any nation, government department, small company, and individual university could now access space directly in an affordable and low risk manner.

Evolution of smallsats enabled new business models in the satellite industry. These low-cost smallsats in LEO (Lower Earth Orbit) radically changed two major satellite business applications, viz., Earth Observation and

\section{Digital Communications.}

Earth Observation business has seen a major impact as smallsats in low earth orbits can provide better quality images of earth than was possible through satellites in higher geostationary orbits. Planet Labs Inc. is a company that designs and manufactures Triple-CubeSat miniature satellites called Doves that are delivered into orbit as secondary payloads on other rocket launch missions to create an earth observation constellation. There are about 120 Doves in orbit, picturing any point on earth at least 7 times per day. Each of these Doves has a life of approximately 3 years post which it needs to be replaced. The ongoing replacement demand for manufacturing and launching these smallsats helps growth of the space economy by providing it a constant flow of business. It is apparent that a business model such as Planet Labs' would have been infeasible without lower cost of space launch and satellites [26].

The second area where smallsats are having a big impact is on the capability to offer global broadband internet services through LEO constellations. Over the last decade, most urban areas have got well covered with broadband mobile internet through optical fibre and radio networks. As such, 4G (Fourth generation) mobile network coverage is widely available and $5 \mathrm{G}$ networks are under deployment. Consumers expect access to broadband internet anytime, anywhere. At the same time, there are large parts of the globe without even second-generation (2G) communication infrastructure. Satellite networks in LEO can provide low latency delivery of broadband internet to all parts of the globe. Further, they can also provide network redundancy in urban areas. This can help in delivering high speed internet to $50 \%$ of the world's population that is currently not connected because of cost or coverage considerations [27]. 
Therefore, several major players, such as OneWeb, SpaceX's Starlink and Amazon's Project Kuiper, are planning to launch communication satellite constellations. Starlink hopes to achieve the above by 2027 with an endgoal of about 12,000 satellites. A figure that will increase the total number of satellites in orbit sixfold. Amazon has filed to launch 3,236 spacecraft in its Kuiper constellation. [28] .

Together, these LEO satellite constellations for both Earth Observation and Communication will create a new Space Wide Web and ongoing demand for both replacement and new satellites along with a range of associated economic activity for management and downstream applications.

This thrust towards smaller satellites has meant that the number of satellites in the LEO have increased rapidly since 2013, as shown in Figure 1 [29]. The trend till 2012 was that $45 \%$ satellites launched in a year would be in the LEO. By $2017, \sim 80 \%$ of total satellites being launched were in the LEO.

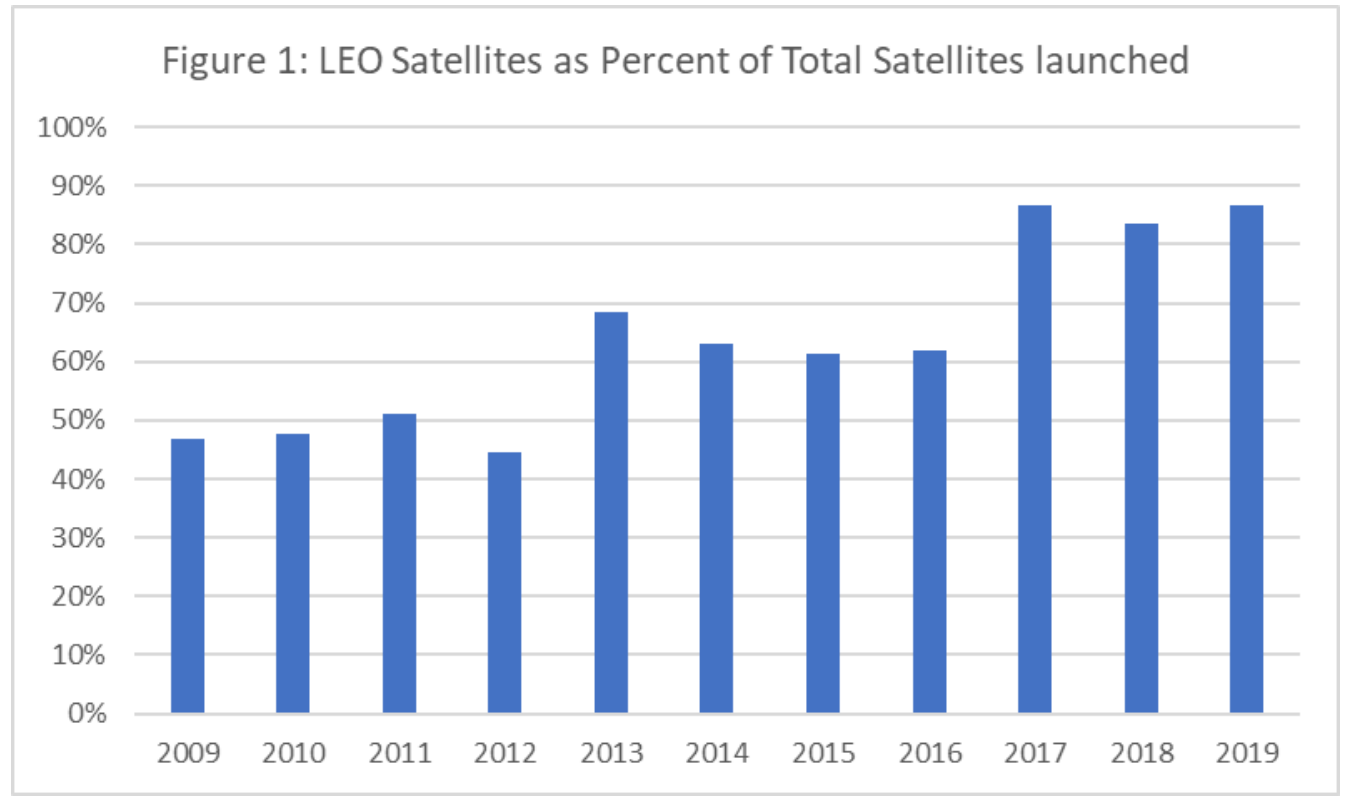

Fig. 1. LEO satellites as percent of total satellites launched.

As the satellite market witnesses growth, the MIT technology Review [30] forecasts that satellites in space may quintuple over the next decade with annual satellite launches increasing to 1,145 in 2025 , in contrast to 388 in 2019, as shown in Figure 2.

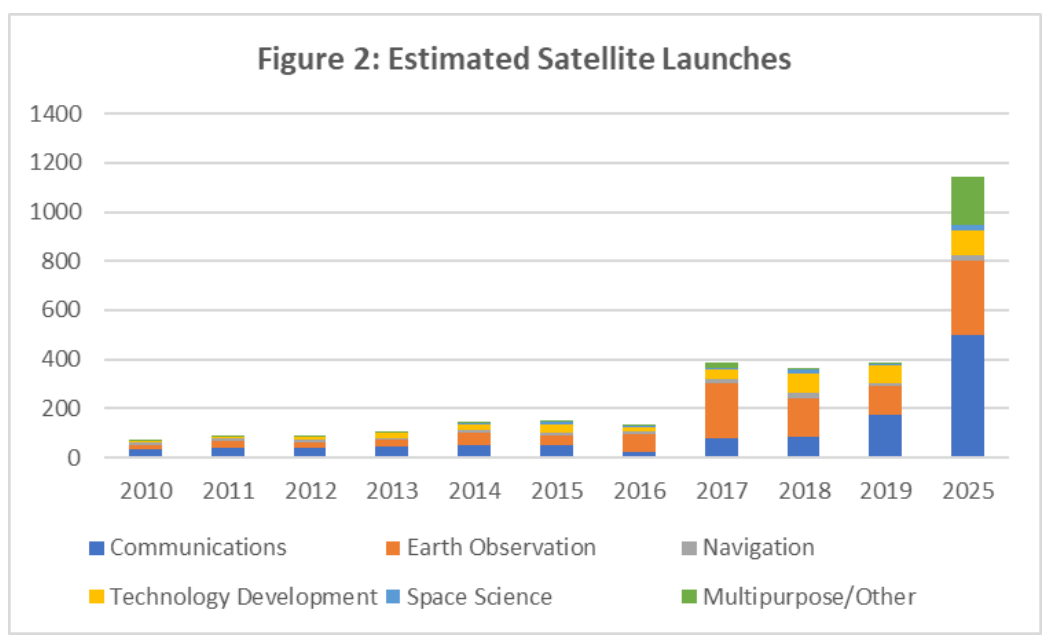


Fig. 2. Estimates satellites launched.

Growth opportunities in smallsat manufacturing and launch are leading to several associated developments. Producing these smallsats with short replacement cycles could lead to not only "digital factories" on Earth, but also the autonomous space assembly of large systems comprising thousands of "smart" nano/microsatellite "Lego" blocks and, ultimately, in-orbit manufacturing of satellites and space vehicles [3].

Launch requirements for these satellites have prompted a surge in small launcher developments, both from agencies (such as Vega from the European Space Agency, Epsilon from the Japan Aerospace Exploration Agency), and startups (such as Rocket Lab, Orbital Express) with several more under development. Additionally, it provides a secondary payload opportunity for large players such as Arianespace, Antrix (PSLV) and SpaceX. [3]

\section{Success of SpaceX}

SpaceX has been the poster child of the private space industry due to its success in changing the industry dynamics with its innovative approach and generation of tremendous value for its investors.

In 2008, SpaceX successfully launched Falcon 1 into orbit, marking a significant milestone in the history of space. Over time and through subsequent launches it has been able to deliver on its promise of reusable rockets and lower the cost of launches. The success of SpaceX in delivering on its promise has led to its valuation soaring from US\$27 Million in 2002 to US\$46 billion in August 2020, as shown in Figure 3 below [31].

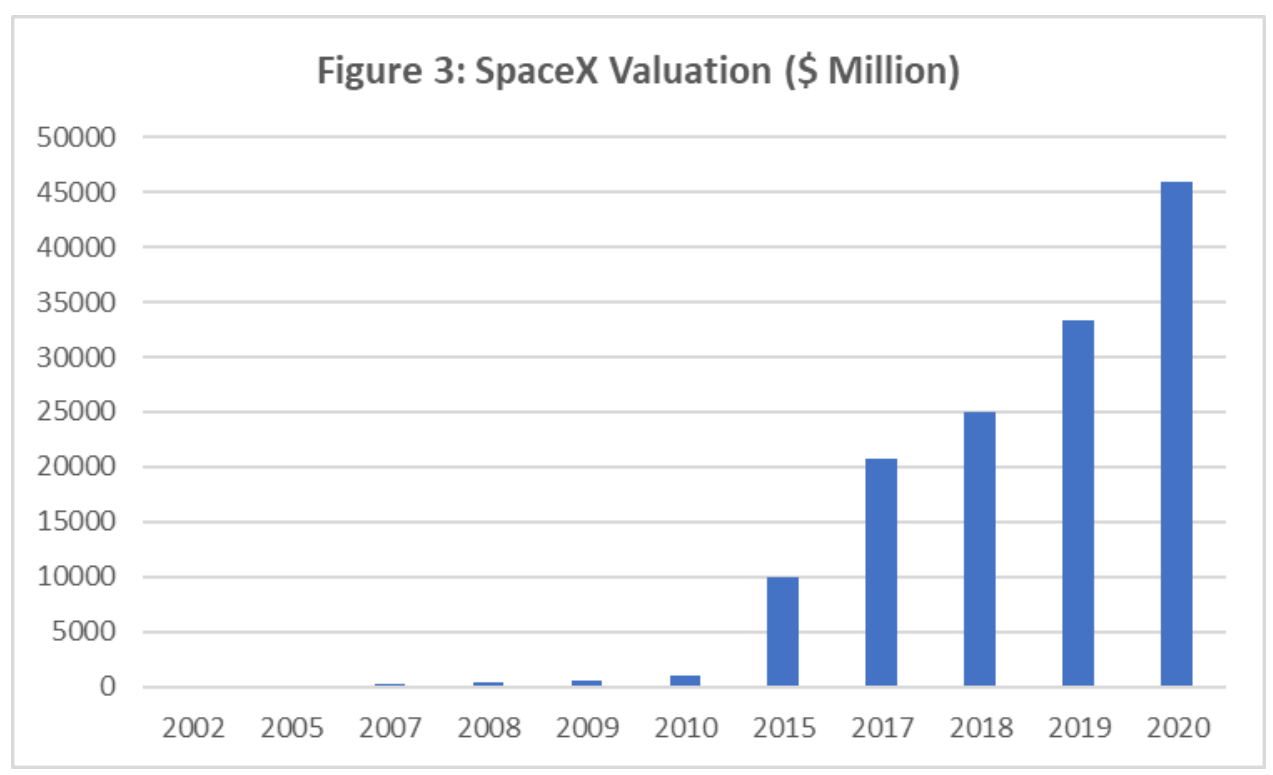

Fig. 3. SpaceX valuation.

This has drawn tremendous interest from both entrepreneurs and investors, as space became not just an exciting, but also a lucrative, investment. Figure 4 shows how SpaceX's success has since sparked a rapid increase in private investments in space. From less than US\$500 million per year in 2009, private investment in space had grown to over US\$5 billion per annum by 2019. [32]. 


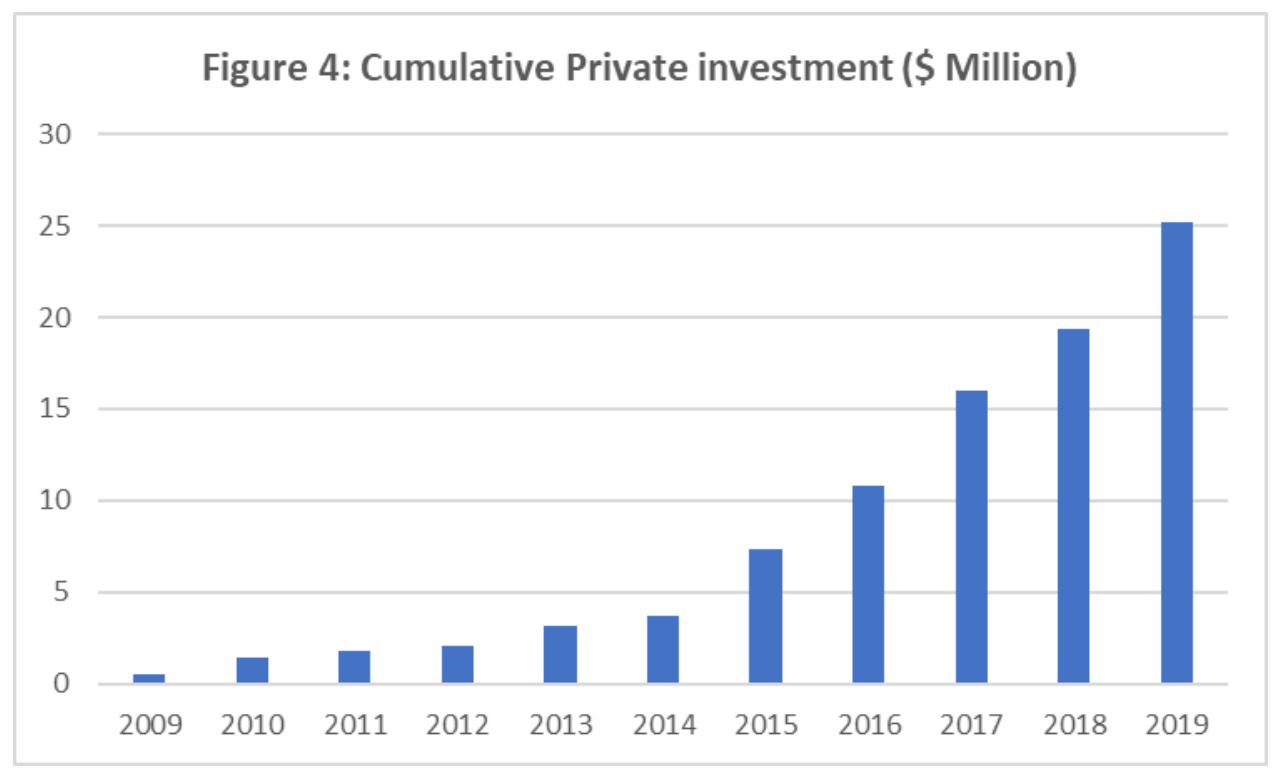

Fig. 4. Cumulative private investments.

The next section offers an analysis of how the space economy is expected to grow in the future and the role that private investment will continue to play in it.

\section{Future Outlook of Space Revenues and Investments}

The analysis and research provided above clearly indicates that the commercial sector has a much higher impact on the monetary size of the space economy than the government sector. While the government may have started space research, the growth of the space economy is now driven primarily by private sector initiatives.

The space economy's growth looks promising over the next decades, as humans look to leverage the earthoriented opportunities (communications, earth observation, etc.) in the near term and the prospects of mining, space tourism, as well as Moon \& Mars expeditions in future. Several organizations have made forecasts of the space economy using slightly different starting points and future assumptions. The Science \& Technology Policy Institute [17] has collated and reviewed some of these forecasts, as provided in Table 4 below.

TABLE 4

Different Projections of the Size of Space Economy

\begin{tabular}{|l|l|l|l|l|}
\hline Institution & Year & $\begin{array}{l}\text { 2016 Space Econ- } \\
\text { omy }\end{array}$ & $\begin{array}{l}\text { Forecast Space } \\
\text { Economy }\end{array}$ & $\begin{array}{l}\text { Compound Annual } \\
\text { Growth Rate }\end{array}$ \\
\hline UBS & 2040 & $\$ 340$ billion & $\$ 926$ billion & $4.3 \%$ \\
\hline Morgan Stanley & 2040 & $\$ 339$ billion & $\$ 1.1$ Trillion & $4.9 \%$ \\
\hline $\begin{array}{l}\text { US Chamber of Com- } \\
\text { merce }\end{array}$ & 2040 & $\$ 383.5$ billion & $\$ 1.5$ Trillion & $6 \%$ \\
\hline Bank of America & 2045 & $\$ 339$ billion & $\$ 2.7$ Trillion & $9 \%$ \\
\hline Goldman Sachs & $\sim 2040$ & $\$ 340$ billion & Multi-trillion $\$$ 's & $9.5 \%$ d \\
\hline
\end{tabular}




\section{Sources: UBS 2018; Morgan Stanley Research 2017; U.S. Chamber of Commerce 2018; Bank of America}

Equity Research 2017; Goldman Sachs Equity Research 2017

According to its report published in 2017, Morgan Stanley estimates that the global space industry could generate more than US\$1 trillion in revenue by 2040 [33]. As per the report, the industry growth in the next 5-7 years is likely to be driven by the launches of LEO satellite constellations and their associated services, while growth after 2026, to a substantial extent, will be determined by what are mentioned as 'second order impacts' in the report essentially this will require the New Space Economy businesses to start pulling their weight from a commercial perspective.

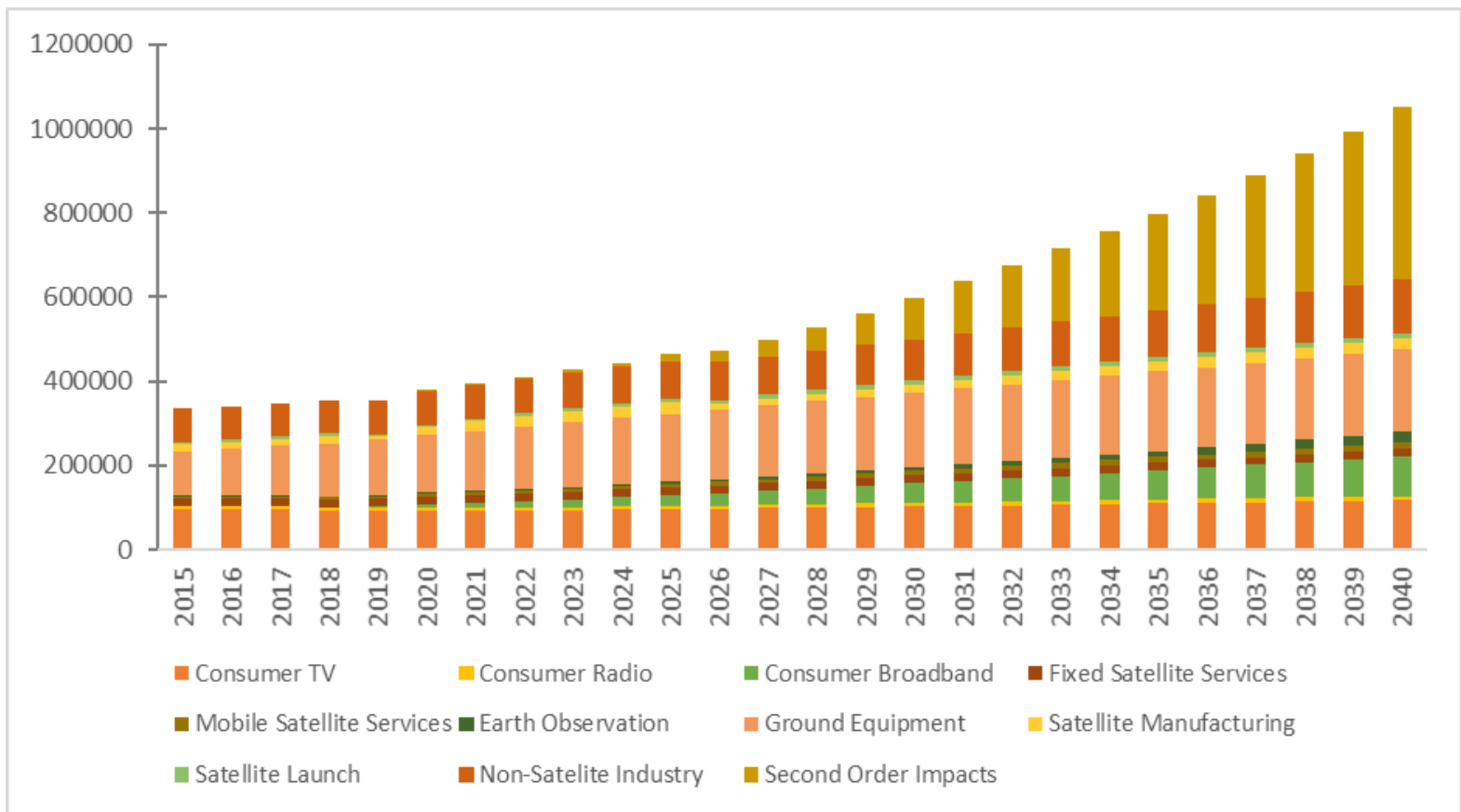

Fig. 5. The global space economy (US\$ million).

It is evident that while the near-term opportunities are satellite-led and relatively well-established, new space opportunities, that is, asteroid mining, space tourism and the colonization of Mars, are novel and riskier, in terms of both economic value and timelines. Significant investments will be required before some of these are realized.

Keeping this in view, a forecast was made for space industry revenues till 2040. Investments required to achieve these revenues were also assessed through quantitative regression analysis.

\section{A. Space Economy Forecast Till 2040}

The historical data for space economy size used earlier in Table 1 was projected forward to forecast the size of the economy till 2040. As per Table 1, the space economy grew at 6.5\% from 2005-2019, with the commercial economy growing at $7.3 \%$ and the government at 3.9\%. Significant recent growth can be attributed to the need for more satellites by a rapidly digitizing world. This is a relatively low-hanging fruit for private sector exploitation. However, it is expected that with increasing scale and greater technical challenges to be overcome in non-satellite business, the growth over the next two decades may be lower than what has been witnessed over the last decade. Hence, the following assumptions have been made for the forecast.

Annual growth rate of Commercial Economy: 6.5\% 
Annual growth rate of Government Economy: 3\%

The above assumptions led to a forecast for the space economy as per Table 5 below.

TABLE 5

Forecast of the Global Space Economy

\begin{tabular}{|l|l|l|l|}
\hline Year & $\begin{array}{l}\text { Commercial Economy } \\
\text { (US\$ billion) }\end{array}$ & $\begin{array}{l}\text { Government Economy } \\
\text { (US\$ billion) }\end{array}$ & $\begin{array}{l}\text { Total Space Economy } \\
\text { (US\$ billion) }\end{array}$ \\
\hline 2019 & 337 & 87 & 424 \\
\hline 2020 & 359 & 90 & 448 \\
\hline 2021 & 382 & 92 & 474 \\
\hline 2022 & 407 & 95 & 502 \\
\hline 2023 & 433 & 98 & 531 \\
\hline 2024 & 462 & 101 & 562 \\
\hline 2025 & 492 & 104 & 595 \\
\hline 2026 & 524 & 107 & 630 \\
\hline 2027 & 558 & 110 & 668 \\
\hline 2028 & 594 & 113 & 707 \\
\hline 2029 & 632 & 117 & 749 \\
\hline 2030 & 673 & 120 & 794 \\
\hline 2031 & 717 & 124 & 841 \\
\hline 2032 & 764 & 128 & 892 \\
\hline 2033 & 814 & 131 & 945 \\
\hline 2034 & 866 & 135 & 1002 \\
\hline 2035 & 923 & 139 & 1062 \\
\hline 2036 & 983 & 144 & 1126 \\
\hline 2037 & 1047 & 148 & 1195 \\
\hline 2038 & 1115 & 152 & 1267 \\
\hline 2039 & 1187 & 157 & 1344 \\
\hline 2040 & 1264 & 162 & 1426 \\
\hline $\boldsymbol{C A G R}$ & $\mathbf{6 . 5 \%}$ & $\mathbf{3 \%}$ & $\mathbf{5 . 9 5 \%}$ \\
\hline & & & \\
\hline
\end{tabular}

The above forecast suggests that the space economy will grow from US\$424 billion in 2019 to US\$1.4 trillion by 2040 , at an annualized rate of about $6 \%$. The size of the commercial economy by 2040 will be US $\$ 1.26$ trillion, while the government economy will be US\$162 billion. This indicates that the share of the government economy in the total space economy would decline from $20.5 \%$ in 2019 to $11.3 \%$ in 2040 .

\section{B. Forecast of Private Investments Required}

The amount of private investment required to support this growth was estimated using historical data for the last 10year period. Cumulative investments were considered as a better predictor for revenues, instead of in-year incremental investments, as cumulative investments are what create capacity for future annualized revenues. Data for the size of the commercial economy was taken from the Space Foundation [15], while the data for incremental private investment was taken from Space Angels [32]. 
TABLE 6

Commercial Economy versus Private Investments (US\$ billion)

\begin{tabular}{|l|l|l|l|}
\hline Year & $\begin{array}{l}\text { Incremental private invest- } \\
\text { ment }\end{array}$ & $\begin{array}{l}\text { Cumulative Private invest- } \\
\text { ment from 2009- }\end{array}$ & $\begin{array}{l}\text { Commercial Economy size } \\
\text { in the year }\end{array}$ \\
\hline 2009 & 0.50 & 0.5 & 162 \\
\hline 2010 & 0.90 & 1 & 170 \\
\hline 2011 & 0.40 & 2 & 193 \\
\hline 2012 & 0.30 & 2 & 208 \\
\hline 2013 & 1.10 & 3 & 228 \\
\hline 2014 & 0.50 & 4 & 251 \\
\hline 2015 & 3.60 & 7 & 246 \\
\hline 2016 & 3.50 & 11 & 262 \\
\hline 2017 & 5.20 & 16 & 308 \\
\hline 2018 & 3.40 & 19 & 329 \\
\hline 2019 & 5.80 & 25.2 & 337 \\
\hline
\end{tabular}

A regression analysis was conducted to see the impact of private investment on the size of the commercial space economy over the period 2009-2019.

The predictive effect of cumulative private investment on future commercial space revenues was confirmed: $b=6.73, t(9)=8.28$ (higher than the critical value of 2.26), $p<.01$. Furthermore, the cumulative private investment also explained a significant proportion of the variance in the commercial revenues, $R^{2}=0.88, F(1,9)=68.62, p<.01$ (see Table 7).

TABLE 7

Regression Results of Cumulative Private Investment on Size of Commercial Economy

\begin{tabular}{cc}
\hline \multicolumn{2}{c}{ Regression Statistics } \\
\hline Multiple R & 0.940247 \\
R Square & 0.884065 \\
Adjusted R & \\
Square & 0.871183 \\
Standard Error & 21.68538 \\
Observations & 11 \\
\hline
\end{tabular}

ANOVA

\begin{tabular}{cccccc}
\hline & & & & Signifi- \\
& $d f$ & $S S$ & $M S$ & $F$ & cance $F$ \\
\hline \multirow{2}{*}{ Regression } & 1 & 32273.4 & 32273.4 & 68.6295 & \\
& & 4 & 4 & 4 & $1.67 \mathrm{E}-05$ \\
Residual & 9 & 4232.30 & 470.255 & & \\
& & 3 & 9 & & \\
Total & 10 & 56505.7 & & & \\
\hline
\end{tabular}




\begin{tabular}{|c|c|c|c|c|c|c|c|c|}
\hline & $\begin{array}{c}\text { Coeffi- } \\
\text { cients }\end{array}$ & $\begin{array}{l}\text { Stand- } \\
\text { ard Er- } \\
\text { ror }\end{array}$ & $t$ Stat & $P$-value & $\begin{array}{c}\text { Lower } \\
95 \%\end{array}$ & $\begin{array}{c}\text { Upper } \\
95 \%\end{array}$ & $\begin{array}{l}\text { Lower } \\
95.0 \%\end{array}$ & $\begin{array}{l}\text { Upper } \\
95.0 \%\end{array}$ \\
\hline & & 9.40060 & 20.1147 & $8.63 \mathrm{E}-$ & & 210.356 & & 210.356 \\
\hline Intercept & 189.0907 & 4 & 4 & 09 & 167.825 & 3 & 167.825 & 3 \\
\hline Cumulative Pri- & & 0.81288 & 8.28429 & $1.67 \mathrm{E}-$ & & 8.57303 & 4.89529 & 8.57303 \\
\hline vate investment & 6.734163 & 3 & 5 & 05 & 4.895293 & 2 & 3 & 2 \\
\hline
\end{tabular}

The equation generated from the linear regression analysis enables the computation of the size of investment required to support the growth in the commercial economy.

Size of commercial economy $=6.734 *$ (size of cumulative private investment since 2009) + US\$189.09 billion (See Table 7 for the coefficients and the intercept)

The best fit regression line and equation are also shown in Figure 6 below. As can be seen, most outliers are in the earlier years when the size of private investment was small. Data over the last five years tracks much closer to the best fit line from regression analysis.

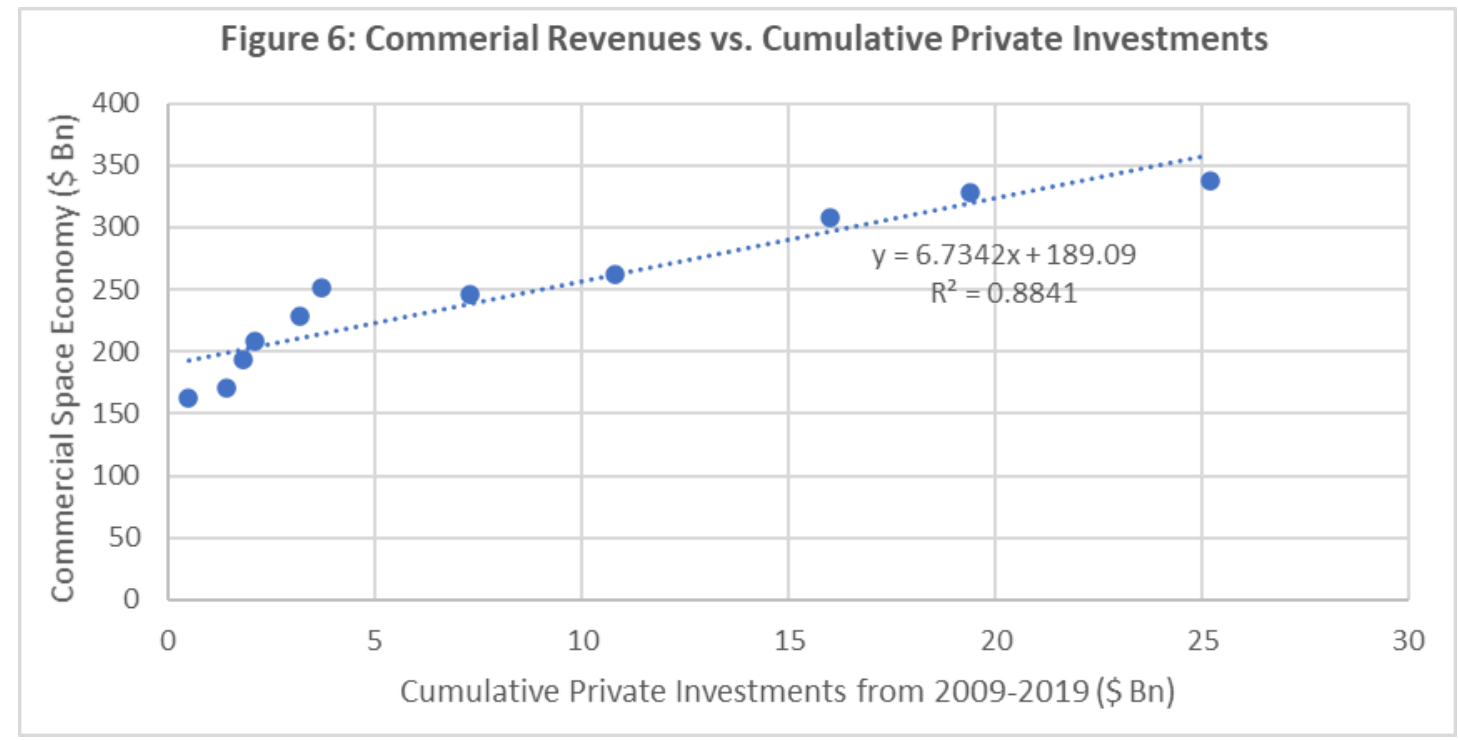

Fig. 6. Commercial revenues vs. cumulate private investments.

This analysis suggests that historically for every US\$1 billion of incremental private investment has led to an annualized increase of US $\$ 6.73$ billion in commercial space industry revenues.

Based on the above analysis, it is expected that to achieve the 2025 forecast of US\$492 billion for the commercial space economy, cumulative private investment will need to grow from US\$25 billion in 2019 to around US\$48 billion by 2025 - translating to an incremental private investment of US $\$ 23$ billion over six years. The buildup of the private investments and commercial economy revenues is provided in Figure 7. 


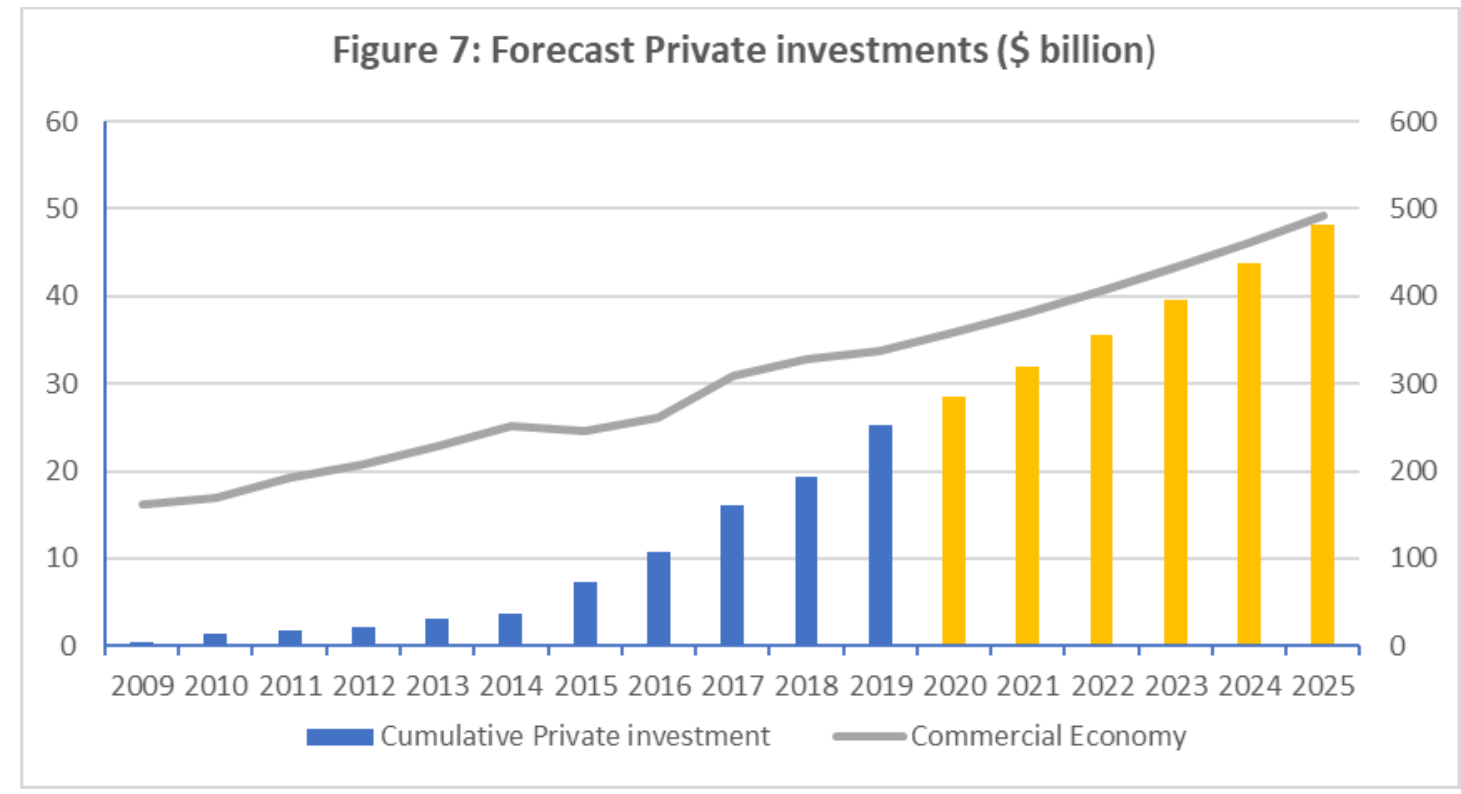

Fig. 7. Forecast private investments (US\$ billion).

Current estimates from Table 6 suggest that the size of the commercial economy will be US\$1.26 trillion in 2040. Applying the equation from the regression analysis, this would require private investments of $\sim$ US $\$ 115$ billion between 2025 and 2040. However, in view of the uncertain nature of space, long term investment forecasts (extending roughly beyond the 2025 timeframe) should be considered only to understand the magnitude of requirements.

\section{Conclusion}

Space offers a massive opportunity for mankind to create new frontiers and technology. While the government may continue to fund some specific projects, the private sector will play an increasingly critical role in this industry. The size of the commercial economy by 2040 is forecasted to reach US $\$ 1.26$ trillion. To achieve this potential, private investments of US\$23 billion are estimated to be required till 2025 and $\sim$ US\$115 billion from the 2025-2040 timeframe.

The actual growth and investment flow in the commercial space economy would likely be determined through a two-step process.

For the next 5-10 years, business outcomes of the satellite constellation launches and Mars missions are expected to determine the investment appetite for the private space sector.

Beyond 2030, growth in the space economy will require that new promising technologies (such as additive manufacturing and space tourism) and their estimated revenue streams start delivering on their potential.

If satellite constellations deliver as per current plans, planned Mars missions are successful, and some of the new technologies and business models start moving to a commercial stage by 2030, it can provide an extremely virtuous cycle of growth and investments.

Considering the allure of space and wealth of the entrepreneurs interested in space, along with diminishing opportunities earthside to deploy all the capital generated by tech entrepreneurs, the Earth may truly not be enough! 


\section{Acknowledgements}

I would like to thank my research advisor Dr. Mritunjay Sharma for his guidance. I would also like to thank my economics teacher for always encouraging me to explore economics, and its intersections with other disciplines, beyond the classroom.

\section{References}

[1] Office of the Historian, Sputnik, 1957, Foreign Service Institute, United States Department of State, n.d. Accessed on: Oct. 25, 2020. [Online]. Available: https://history.state.gov/milestones/1953-1960/sputnik

[2] G. Genta, "Private Space Exploration: A New Way for Starting a Spacefaring Society?," Acta Astronautica, vol. 104, no. 2, pp. 480-486, Nov. 2014. Accessed on: Oct. 25, 2020. [Online]. Available: http://dx.doi.org/10.1016/j.actaastro.2014.04.008

[3] M. N. Sweeting, "Modern Small Satellites - Changing the Economics of Space," Proceedings of the IEEE, vol. 106, no. 3, March 2018. Accessed on: Oct. 25, 2020. [Online]. Available:

https://ieeexplore.ieee.org/document/8303876

[4] P. Barbaroux, "The metamorphosis of the world space economy: investigating global trends and national differences among major space nations' market structure," Journal of Innovation Economics \& Management, vol. 20, no. 2, pp. 9 - 35, 2016. Accessed on: Oct. 25, 2020. [Online]. Available: https://doi.org/10.3917/jie.020.0009

[5] Heiney, A. 1980s: All Eyes Focus on Space Shuttle, NASA's John F Kennedy Space Center, June 2012. Accessed on: Oct. 25, 2020. [Online]. Available: https://www.nasa.gov/centers/kennedy/about/history/timeline/80s-decade.html

[6] National Aeronautics and Space Administration. About the Hubble Space Telescope, Dec. 2018. Accessed on: Oct. 25, 2020. [Online]. Available: https://www.nasa.gov/mission_pages/hubble/story/index.html

[7] A. F. G. Brown, “Accidents, Engineering, and History at NASA 1967-2003," Ph.D. dissertation. Program in Science, Technology and Society, Mass. Inst. of. Tech., Cambridge, 2009. Accessed on: Oct. 25, 2020. [Online]. Available: https://history.nasa.gov/SP-2006-4702/chapters/chapter12.pdf

[8] M. Weinzierl, "Space, the final economic frontier," Journal of Economic Perspectives, vol. 32, no. 2, pp. 173-92, 2018. Accessed on: Oct. 25, 2020. [Online]. Available: https://doi.org/10.1257/jep.32.2.173

[9] C. Mellow, "The rise and fall and rise of iridium," Air and Space Magazine, Sept. 2004. Accessed on: Oct. 25, 2020. [Online]. Available: https://www.airspacemag.com/space/the-rise-and-fall-and-rise-of-iridium$\underline{5615034 /}$

[10] C. Henry, Iridium ends legacy satellite service, switches all traffic to next fleet, Spacenews, Feb. 6, 2019. Accessed on: Oct. 25, 2020. [Online]. Available: https://spacenews.com/iridium-ends-legacy-satelliteservice-switches-all-traffic-to-next-fleet/

[11] Blue Origin, Millions of People Living and Working in Space. Accessed on 24 September 2020. [Online]. Available: https://www.blueorigin.com/

[12] J. Matthews, The Decline of Commercial Space Launch Costs, Deloitte Consulting LLP. Accessed on Oct. 25, 2020. [Online]. Available: https://www2.deloitte.com/us/en/pages/public-sector/articles/commercialspace-launch-cost.html 
[13] D. Morgan and C. E. Behrens, "National Aeronautics and Space Administration Overview, FY2009 Budget, and Issues for Congress," Mar. 6, 2009. Accessed on Oct. 25, 2020. [Online]. Available: https://digital.library.unt.edu/ark:/67531/metadc87389/

[14] L. M. Dooley, "Case study research and theory building," Advances in Developing Human Resources, vol. 4, no. 3, pp. 335-354, Aug. 2002. Accessed on: Oct. 25, 2020. [Online]. Available: https://doi.org/10.1177/1523422302043007

[15] Space Foundation, "The Space Report 2018: The Authoritative Guide to Global Space Activity," Space Foundation, CO, USA, 2018. Accessed on: Oct. 25, 2020. [Online]. Available: https://www.thespacereport.org/register/the-space-report-2018/

[16] J. Foust, Commerce Department to develop new estimate of the size of the space economy, Spacenews, January 2, 2020. Accessed on: Jan. 10, 2020. [Online]. Available: https://spacenews.com/commercedepartment-to-develop-new-estimate-of-the-size-of-the-space-economy/

[17] K. W. Crane, E. Linck, B. Lal, and R. Y. Wei, "Measuring the Space Economy: Estimating the Value of Economic Activities in and for Space," Science and Technology Policy Institute, March 2020. Accessed on: Oct. 30, 2020. [Online]. Available: https://www.ida.org/-/media/feature/publications/m/me/measuringthe-space-economy-estimating-the-value-of-economic-activities-in-and-for-space/d-10814.ashx

[18] C. Stone, "Perception vs. reality in NASA's commercial crew and cargo program," The Space Review, October 8, 2012. Accessed on: Oct 30, 2020. [Online]. Available: https://www.thespacereview.com/article/2166/1\#

[19] OECD, The Space Economy in Figures: How Space Contributes to the Global Economy, OECD Publishing, Paris, 2019. Accessed: Oct. 25, 2020. [Online]. Available: https://doi.org/10.1787/c5996201en

[20] G. Autry, "The next economic revolution just (re)launched: Congratulate SpaceX, thank NASA, ” Forbes, April 1, 2017. Accessed on: Oct. 25, 2020. [Online]. Available: https://www.forbes.com/sites/gregautry/2017/04/01/the-next-economic-revolution-just-relaunchedcongratulate-spacex-thank-nasa/\#70a9f25a8c7e

[21] H. W. Jones, "The Recent Large Reduction in Space Launch Cost, National Aeronautics and Space Administration, 2018," NASA, 2020. Accessed: Oct. 25, 2020. [Online]. Available: https://ntrs.nasa.gov/archive/nasa/casi.ntrs.nasa.gov/20200001093.pdf

[22] R. Zafar, SpaceX Could Bring Starship Launch Costs Down To \$10/kg Believes Musk, WCCFTECH, May 8, 2020. Accessed on: Oct. 25, 2020. [Online]. Available: https://wccftech.com/spacex-launch-costs-downmusk/

[23] A. Chaikan, "Is SpaceX changing the rocket equation?" Air \& Space Magazine, Jan. 2012. Accessed on: Oct. 25, 2020. [Online]. Available: https://www.airspacemag.com/space/is-spacex-changing-the-rocketequation-132285884/

[24] H. W. Jones, "The Impact of Lower Launch Cost on Space Life Support," NASA, Dec. 2015. Accessed on: Oct. 25, 2020. [Online]. Available:

https://ntrs.nasa.gov/archive/nasa/casi.ntrs.nasa.gov/20180007067.pdf

[25] "Isro sends 104 satellites in one go - breaks Russia's record," Economic Times, Feb. 15, 2017. Accessed on: Oct. 25, 2020. [Online]. Available: https://economictimes.indiatimes.com/news/science/isro-sends104-satellites-in-one-go-breaks-russias-record/articleshow/57159365.cms\#

[26] S. Clark, Rocket Lab Plans Next Launch Saturday, Closes in on First Mission from Virginia, Spaceflight Now, July 3, 2020. Accessed on: Oct. 25, 2020. [Online]. Available:

https://spaceflightnow.com/2020/07/03/rocket-lab-aims-for-saturday-launch-in-new-zealand-closes-in-onfirst-mission-from-virginia/ 
[27] Goldman Sachs, Space, The Next Investment Frontier, Goldman Sachs, NY, USA, April 4, 2017. Accessed on: Oct. 25, 2020. [Online]. Available:

http:/www.fullertreacymoney.com/system/data/files/PDFs/2017/October/4th/space\%20-

$\% 20$ the $\% 20$ next $\% 20$ investment $\% 20$ frontier $\% 20-\% 20$ gs.pdf

[28] "Large LEO satellite constellations: Will it be different this time?" McKinsey Quarterly, May 4, 2020. Accessed on: Oct. 25, 2020. [Online]. Available: https:/www.mckinsey.com/industries/aerospace-anddefense/our-insights/large-leo-satellite-constellations-will-it-be-different-this-time

[29] Union of Concerned Scientists, UCS Satellite Database, Union of Concerned Scientists, MA, USA, August 2020. Accessed on: Oct. 25 2020. [Online]. Available: https://www.ucsusa.org/resources/satellite-database

[30] T. R. Mosley, E. Winick, and K. Kakaes, "Satellite constellations orbiting Earth quintuple," MIT Technology Review, June 26 2019. Accessed on: Oct. 25, 2020. [Online]. Available: https:/www.technologyreview.com/2019/06/26/755/satellite-constellations-orbiting-earth-quintuple/

[31] J. Young, "In Spite of Elon Musk, SpaceX's Valuation Has Surged 122,233\% Since 2002”, CNN, Dec. 7, 2019. Accessed on: Oct. 25, 2020. [Online]. Available: https:/www.ccn.com/in-spite-of-elon-muskspacexs-valuation-has-surged-122233-since-2002/

[32] Space Angels, "Space Investment Quarterly Q4, 2019, ” Space Angels, USA, Jan. 14, 2019. Accessed on: Mar. 1, 2020. [Online]. Available: https://www.spaceangels.com/post/space-investment-quarterly-q4-2019

[33] Morgan Stanley, “Space: Investing in the Final Frontier, ” Morgan Stanley, USA, 2017. Accessed on: Oct. 25, 2020. [Online]. Available: https://www.morganstanley.com/ideas/investing-in-space 